\begin{tabular}{|c|c|}
\hline 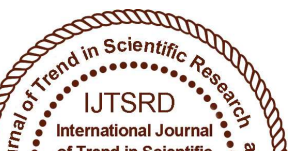 & $\begin{array}{l}\text { International Journal of Trend in Scientific } \\
\text { Research and Development (IJTSRD) }\end{array}$ \\
\hline 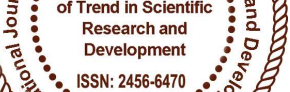 & International Open Access Journal \\
\hline 000 & ISSN No: 2456 - 6470 | www.ijtsrd.com | Volume - 2 | Issue - 5 \\
\hline
\end{tabular}

\title{
Automated Grass Cutter Robot Based on IoT
}

\author{
Neha $^{1}$, Syeda Asra ${ }^{2}$ \\ ${ }^{1}$ Student, ${ }^{2}$ Associate Professor \\ Appa Institute of Engineering and Technology, Kalaburagi, Karnataka, India
}

\begin{abstract}
Automation is rapidly growing in the present technology. So automation plays a vital role in the agricultural field which is helpful for the farmers. In the earlier days, the grass cutters used were manually handheld devices. Because of this, there was pollution and loss of energy as they used gas and petrol engines. So the old grass cutters need to be replaced by automated ones, where the system will work for guidance and obstacle detection using battery as a power source. And it used Arduino UNO microcontroller board as the main controller of the system, Ultrasonic sensor for object detection, a NODE MCU for Wi-Fi connection, a linear blade for cutting the grass, and a motor drive for the wheels of the Robot. This is fully automated and renewable energy based project.
\end{abstract}

Keywords: Robot, Automation, IOT, $M C U$

\section{INTRODUCTION}

In large size of lawn in the park, schools, college are maintained manually. The gardener used hand scissors to cut and maintain lawn regularly which also takes more time. It is not easy and also very difficult to maintain uniform size. Hence this works to make a battery powered automatic grass cutter. The unskilled gardener is enough to operate this grass cutter. The battery powered grass cutter is easy to operate and it consists of rotary blade, roller etc. The blade removes the extra growth of the lawn and roller gives light pressure to the top surface of lawn. It gives fine look to the lawn and uniform look throughout the lawn. The Project work was very great successful one. It is used to maintain lawn of our college auditorium for lawn maintenance. This Project of a battery powered lawn mower will reduce both environmental and noise pollution. This design is meant to be an alternate green option to the popular and environmentally hazardous gas powered lawn mower. Ultimately, the consumer will be doing more for the environment while doing less work in their daily lives. The hope is to keep working on this project until a suitable design can be implemented and then be ultimately placed on the market, The ultrasonic sensor used to object detection and the robot in all possible directions in the environment are Forward, Backward, Right, Left and Arm movement through IOT. Special movements for arm in enhanced with the gripper.

II. LITERATURE SURVEY

Review on Fully Automated Solar Grass Cutter February [2018]

Tushar Baingane

According to the author, In today's world, automation in almost everything plays a very important role in investigating, the grass cutters before used were manually handheld but now they are implemented the grass cutters which are automated. The automated grass cutter use a solar panel for the battery energy and they used IR sensor for obstacle detectation. They implemented the advanced and automated grass cutter with the high efficiency and accurate because it has the ability to sense the objects.

Self-Efficient and Sustainable Solar Powered Robotic Lawn Mower. (December 2015)

Srishti Jain, Amar Khalore and ShashikantPatil

According to the author a solar powered vision based robotic lawn mower which provides automatic lawn mower that will helps the user the independence to cut the grass with less effort. Unlike other robotic lawn mowers, this design requires no perimeter wires to maintain the robot within the lawn and also with less human effort in the manual mode operation. Through an array of sensors safety takes major consideration in 
the device, this robot will not only stay on the lawn, it will avoid and detect objects and humans. Here they used a $12 \mathrm{v} 310 \mathrm{~mA}$ solar panel in their project. each contributing to $0.5 \mathrm{v}$ each. They could attach a battery but as the lead acid rechargeable battery used is rated $12 \mathrm{v} 1.2 \mathrm{Ah}$, it won't be overcharged due to the small output of solar panel. To detect the obstacles, they used IR sensors. There are two sensors, one on each side. This is because in case the obstacle is on the left then it will move in right direction and if the right sensor detects the obstacle then it goes towards the left.[1] But disadvantage is that sometimes response of the system is too slow so in real time high end DSP processors is recommended that can process much faster.

\section{Automated Solar Grass Cutter (February 2017)}

Ms. Rutuja A. Yadav, Ms. Nayana V. Chavan, Ms. Monika B. Patil, Prof. V .A. Mane

According to the author a daily purpose robot which is able to cut the grass in the lawn. The system will have some automation work for guidance and other obstacle detection and the power source that is battery and a solar panel will be attached on the top of the robot because of this reduces the power problem. Automated solar grass cutter are increasingly sophisticated, are self-docking and some contain rain sensors if necessary, nearly eliminating human interaction. The system is switched to automatic mode in which the robot's infrared sensors make a comparison between, cut and uncut the grass. The mower continues this process until it completes the job. The system uses $12 \mathrm{v}$ batteries to power the vehicle movement motors as well as the grass cutter motor. They also use a solar panel to charge the battery so that there is no need of charging it externally. The grass cutter and vehicle motors are interfaced to an 8051 family microcontroller that controls the working of all the motors. It is also interfaced to an ultrasonic sensor for object detection. The microcontroller moves the vehicle motors in the forward direction in case no obstacle is detected. If in case obstacle is detected by the sensor then the microcontroller stops the grass cutter motor so as to avoid any damage to the object/human/animal coming. [2]

\section{Solar Based Grass Cutting (January-June 2017)}

Ms. Bhagyashri R. Patil, Mr. Sagar S. Patil

According to the author, human enlargement in many countries there are studies and trials going on the solar energy and the wind energy, so they made their new concept solar power grass cutting machine. In this concept they cut the grass on the agricultural land or small plants in lawns and gardens. The design of solar powered agricultural equipment will include direct current (DC) motor, a rechargeable battery, solar panel, a stainless steel blade and control switch. The automatic grass cutting machine is going to perform the grass cutting operation by its own which means no manpower is essential. The purpose of the project here is to design and build a remote controlled grass cutter. The device consist of linear blades and it does not affected by climatic conditions. They have used many components for preparing grass cutter like DC Motor(3) for rotating the wheels and blade, wheels(4), battery, Solar panel, IR sensor, Collapsible blade. There are two main components such as transmitter and receiver. Transmitter continuously transmits the rays if any obstacle come in front of grass cutter then the rays are reflected back towards the receiver. The receiver receives the signal in the serial form from encoder but microcontroller requires parallel data for communication so receiver sends data to decoder to convert data in the parallel form and then it is passed to microcontroller.[4]

Solar bases wireless grass cutter ( IJSTE International Journal of Science Technology \& Engineering, May 2016)

According to the author, The idea of autonomous machine used to reduce man power with efficient work has given. Mainly this project explains application of green energy. This knowledge can be used in agricultural field as a future scope.

Sensor based multipurpose agricultural cutter (International Research Journal of Engineering and Technology (IRJET))

According to the author, it gives description of multipurpose grass cutter which is sensor based for special purposes like in grass trimming, hedge trimming etc. utilization of sensor and design calculation are used in proposed system.

\section{SN Eno}

According to the author, A robot was designed that operates on an on-board, solar charged battery has been designed by the French manufacturer SN Eno. The Robo-Mower4 the capability of steering itself across a person's lawn. This robot called the Atawa A34, uses built-in infrared sensors to avoid obstacles. This system uses wires buried beneath the surface of the ground to control it [5]. 


\section{CONCLUSION:}

According to the above authors automation plays a very important role in today's world so by replacing all the human intervened lawn movers they proposed an automated battery powered grass cutter for the removal of unnecessary grass from the lawn hence by protecting the environmental pollution as it replaces fuel based grass cutters by battery powered automated ones.

\subsection{PROBLEM STATEMENT}

In the time where technology is merging with environmental awareness, consumers are looking for ways to contribute to the relief of their own carbon footprints. Pollution is manmade and can be seen in our own daily lives, more specifically in our own homes. Gas powered lawnmower are in $90 \%$ of U.S. home and they create $5 \%$ of the total U.S. pollution. Green technology initiatives are being support by both the government and cooperates business. Our new design for an old and outdated habit will help both the consumer and the environment. Battery powered automatic lawn mower will relieve the consumer from mowing their own lawns and will reduce both environmental and noise pollution. This design is meant to be an alternate green option to the popular and environmentally hazardous gas powered lawn mower. Ultimately, the consumer will be doing more for the environment while doing less work in their daily lives.

\subsection{SCOPE OF THE PROJECT:}

To allow for greater flexibility in the design, a custom built platform will be used. Much experience has already been gained with the other sensors working on the first two generations of autonomous lawn mowers. This is the key system that will enable the mower to recognize objects, avoid them, and can move also in a pattern.

\section{PROPOSED DESIGN METHODOLOGY 3.1. BLOCK DIAGRAM DESCRIPTION}

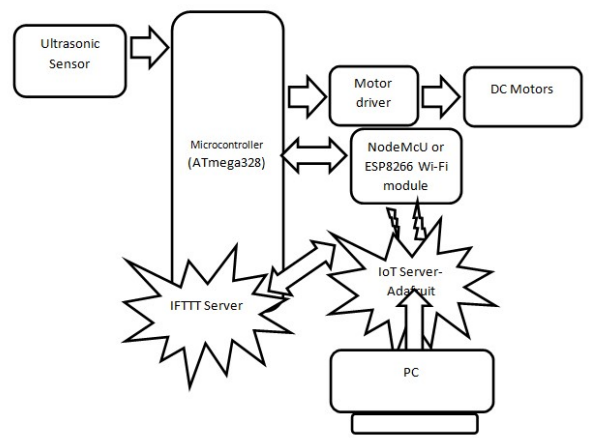

Fig 3.1: Block diagram of grass cutter robot.

\section{WORKING}

The design contains a microcontroller, ultrasonic sensor, DC motor, node MCU all these together combined we get a grass cutter robot. I used only an ultrasonic sensor to detect if the robot was heading into an object. Safety is the main concern when designing a robot with blades. Determining where to place our sensors is crucial to the overall effectiveness of our design. The microprocessor must be in the robot to protect it from the natural elements. Ultrasonic sensor will be mounted directly in front of the robot for maximum detection. Batteries are use for power generation for the robot movement and the battery is rechargeable. Node MCU is used as Wi-Fi model to connect the system to the internet. There is a need for Ad fruit server login for creting toggle feeds for the robot such as forward, reverse, left, right and motor $\mathrm{ON}$.

\section{COMPONENTS DESCRIPTION}

Arduino ATmega328P: Arduino is brain of overall system. Arduino is single-board microcontroller intended to make building interactive objects or environments more accessible. Introduced in 2005, the Arduino's designers sought to provide an inexpensive and easy way for hobbyists, students, and professionals to create devices that interact with their environment using and actuators.

DC Motor: A DC motor relies on the fact that like magnet poles repel and unlike magnetic poles attract each other. A coil of wire with a current running through it generates a electromagnetic field aligned with the center of the coil. By switching the current on or off in a coil its magnetic field can be switched on or off or by switching the direction of the current in the coil the direction of the generated magnetic field can be switched $180^{\circ}$. A simple DC motor typically has a stationary set of magnets in the stator and an armature with a series of two or more windings of wire wrapped in insulated stack slots around iron pole pieces (called stack teeth) with the ends of the wires terminating on a commutator.

Advantages of a brushed DC motor include low initial cost, high reliability, and simple control of motor speed. Disadvantages are high maintenance and low life-span for high intensity uses. Maintenance involves regularly replacing the carbon brushes and springs which carry the electric current, as well as cleaning or replacing the commutator. These 
components are necessary for transferring electrical power from outside the motor to the spinning wire windings of the rotor inside the motor. Brushes consist of conductors.

$>$ IR Sensors: A Sensor converts the physical parameter (for example: temperature, blood pressure, humidity, speed, etc.) into a signal which can be measured electrically. Sensors are sophisticated devices that are frequently used to detect and respond to electrical or optical signals to detect and avoid the object to reduce the chances of failure of blade.

\section{RESULTS AND DISCUSSION}

Integrating features of all the hardware components used have been developed in it. Presence of every module has been reasoned out and placed carefully, thus contributing to the best working of the unit. Secondly, using highly advanced IC's with the help of growing technology, the project has been successfully implemented. Thus the project has been successfully designed and tested. This lawn mower will meet the challenge of environmental production and low cost of operation since there is no cost for fueling. A lawn mower has been developed for the use of residences and establishments that have lawns where tractor driven mowers could not be used.

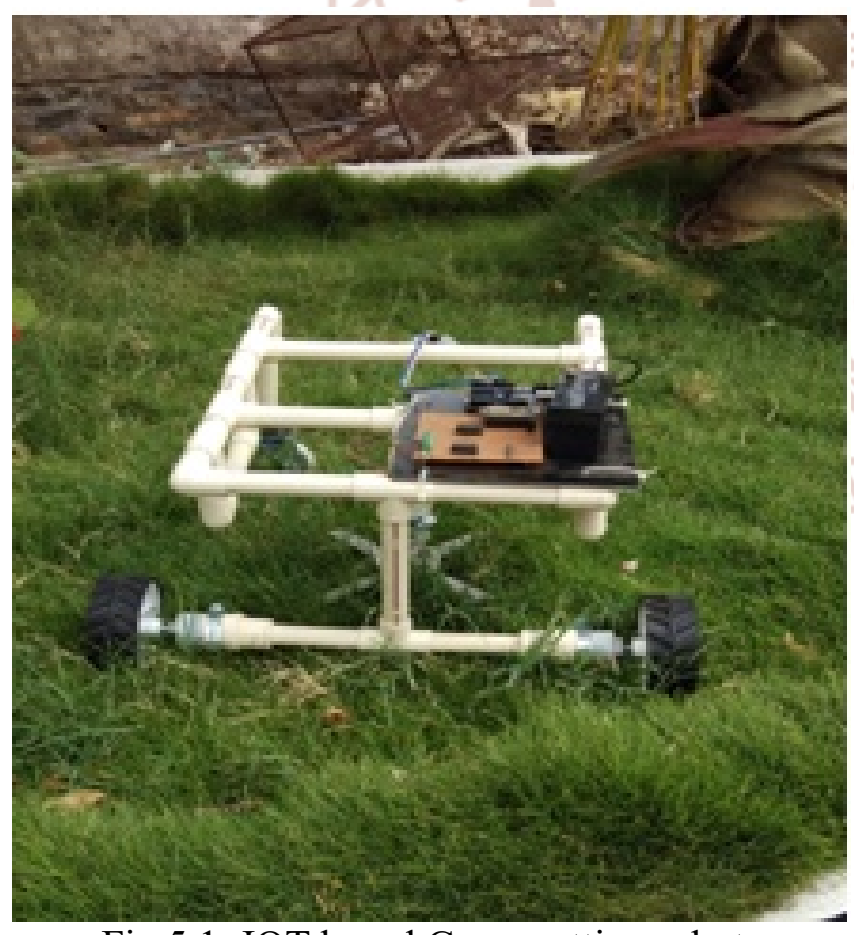

Fig 5.1: IOT based Grass cutting robot.

\section{CONCLUSION}

Main Drawback of the Subsisting System is it need a separate person to operate the Robot, so to overcome this drawback a system was implemented for fully automated battery powered grass cutter. As the technology is getting advanced, features of grass cutters are also enhanced. The designed Model is highly efficient and accurate as it detects the objects and stops the movement. Thus, the Design and implementation of the project has been successful. Since there is no cost of fuel and any kind of pollution as the present system uses battery as a power source, the designed Robot will meet the Challenge of low cost of operation and a renewable energy.

\section{REFERENCE}

1. Srishti Jain, Amar Khalore, Shashikant Patil. SelfEfficient and Sustainable Solar Powered Robotic Lawn Mower in International Journal of Trend in Research and Development (IJTRD). Vol.2 (6), December 2015.

2. Ms. Rutuja A. Yadav, Ms. Nayana V. Chavan, Ms. Monika B. Patil, Prof. V .A. Mane. Automated Solar Grass Cutter in International Journal of Scientific Development and Research(IJSDR). Vol.2, February 2017.

3. Ms. Bhagyashri R. Patil, Mr. Sagar S. Patil. Solar Based Grass Cutting in International Journal of Electrical and Electronics Engineers (IJEEE). January-June 2017.

4. Emest L. Hall. A survey of robot lawn mover, available from Emest L. retrieved on October 06 2015.

5. Ms. Bhagyashri R. Patil, Mr. Sagar S. Patil. Solar Based Grass Cutting in International Journal of Electrical and Electronics Engineers (IJEEE). January-June 2017. 